\title{
Managers as Paranoid Strategists: A Study of the Nature, Causes and Consequences of Competitive Paranoia
}

\author{
Lewis K. S. Lim ${ }^{1,2} \&$ Abhishek Pathak ${ }^{1}$ \\ ${ }^{1}$ Nanyang Business School, Nanyang Technological University, Singapore \\ ${ }^{2}$ Institute on Asian Consumer Insight, hosted by Nanyang Technological University, Singapore \\ Correspondence: Lewis K. S. Lim, Associate Professor of Marketing Practice and ACI Fellow, Nanyang \\ Business School, Nanyang Technological University, S3-B2C-95 Nanyang Avenue, 639798 Singapore. Tel: 65- \\ 6790-4095. E-mail: lewislim@pmail.ntu.edu.sg
}

Received: September 22, 2013 Accepted: November 1, 2013 Online Published: November 18, 2013

doi:10.5539/ijbm.v8n24p84 URL: http://dx.doi.org/10.5539/ijbm.v8n24p84

\begin{abstract}
Prior research alludes to the possibility that managers often suffer from a biased pattern of competitive cognition, such that they systematically assess that their competitors will make more threatening moves than the competitors are actually making. However, few studies shed light on the true nature, causes, and performance consequences of such a cognitive paranoia. This paper attempts to fill the knowledge gap. Through a strategy simulation study, we found that participants indeed generally predicted lower prices and larger advertising expenditures than were the actual moves made by their competitors. However, the degree of paranoia was reduced as participants gain experience. We also found that paranoid teams tended to be those that were highly preoccupied with competitive planning. Interestingly, while being paranoid initially did not matter to firm performance, teams that grew more paranoid toward the late stage of the simulation tended to actually improve their performance over time, suggesting that a "seasoned" form of paranoia may in fact benefit firm performance. The theoretical and practical implications of these results are discussed.
\end{abstract}

Keywords: managerial cognition, cognitive bias, competitive marketing behavior, strategic thinking, markstrat simulation

\section{Introduction}

Research in competitive marketing behavior has shown that managers often have biased patterns of cognitions and behavior in competitive settings. For example, managers tend to over-rate the aggressiveness of competitors that have undertaken major market actions (Prabhu \& Stewart, 2001), over-react to competitors' price cuts and sales promotion activities (Dickson \& Urbany, 1994; Leeflang \& Wittink, 1996), and over-escalate their commitment to rivalry with competitors (Zajac \& Bazerman, 1991). These biased patterns suggest that managers often are overly competitive (Armstrong \& Collopy, 1997; Griffith \& Rust, 1997) and overly wary of competitors' motives (Kalra \& Soberman, 2008).

Such a bias may affect the accuracy of managers' competitive assessment, in that they may systematically predict that their competitors will make more threatening moves (e.g., lower prices, greater advertising expenditures) than the competitors are actually making. Specifically, managers may possess a certain "paranoia" about what their competitors are contemplating to do next. If such a paranoia commonly exists, then the competitor assessment process at many firms is likely to be fraught with errors, and occurrences of misunderstanding among industry players, possibly leading to price wars (Heil \& Helsen, 2001) will rise. Given that competitor assessment is such a central strategic planning activity (Day \& Wensley, 1988; Deshpande \& Gatignon, 1994) that has a direct bearing on the firm's formulation of competitive strategy and its pursuit of competitive advantage (Aaker, 2007; Porter, 1980), a few research questions become worthy of investigation. First, to what extent do managers overestimate the threat posed by key competitors and is this competitive paranoia persistent over time (for example, do managers become less paranoid about competitors' next moves as they gain experience in competitor assessment)? Second, what organizational practices give rise to this competitive paranoia among managers (for example, does preoccupation with competitive planning cause managers to become paranoid about competitors' next moves)? Third, what are the performance consequences of competitive paranoia (for example, does a paranoia tendency affect the quality of managers' competitive 
decisions and, consequently, the firm's financial performance)?

The purpose of this article is to examine the nature, drivers, and outcomes of competitive paranoia. Via a simulated competition setting, we studied how managers make predictions of their competitors' pricing and advertising decisions over time. Our data reveal that, early in the simulation, managers were generally inaccurate in predicting their competitors' next moves. Specifically, they predicted lower prices and larger advertising expenditures than were the actual moves made by their competitors, hence exhibiting a competitive paranoia tendency. However, in the late stage of the simulation, the degree of paranoia was reduced. The data also show that the degree of competitive paranoia was associated with the amount of time managers put into competitive analysis and planning, hence suggesting that preoccupation with competitive assessment leads one to become paranoid of competitors. Finally, the data indicate that, while initial competitive paranoia did not impact firm performance in the early stage of the simulation, teams that grew more paranoid toward the late stage of the simulation tended to also improve their performance over time. This result suggests that a learned or "seasoned" form of paranoia (as opposed to the innate "amateurish" form) may in fact be beneficial to decision making quality and firm performance.

This article contributes to theory and practice of competitive marketing behavior in several ways. First, the study sheds light on the phenomenon of competitive paranoia, a systematic cognition bias that is not yet well understood in the competitive cognition literature. With the exception of Clark and Montgomery (1996) who studied the existence and performance effects of a form of paranoia (measured by the number of reactions a firm perceives its competitor has made to its past actions), the literature rarely, if ever, focuses on this phenomenon despite its significance to competitive behavior research. We advance Clark and Montgomery's (1996) study by relating paranoia to accuracy in prediction about a competitor's future actions. Second, the study presents empirical evidence of competitive paranoia that indicates the extent to which it occurs as well as its persistence. Further, the study provides empirical documentation of a plausible driver of paranoia, namely preoccupation with competitive planning. This finding offers insights into the genesis of competitive cognition bias and how it perpetuates among decision makers dealing with competition. Third, the study empirically documents the performance effects of competitive paranoia. Because the effects suggest that paranoia can in fact be beneficial to firm performance (contrary to what intuition and conventional wisdom may suggest), this study offers both theoretical and practical insights into the dynamics of managerial behavior in competitive settings.

\section{Competitive Paranoia: Its Nature, Causes and Consequences}

The normative competitive strategy literature (e.g., Czepiel, 1992; Porter, 1980) has, for decades, emphasized the need for managers to properly assess the motives, intentions, and likely actions of competitors so as to formulate effective strategies and countermoves. In parallel, game theory research (e.g., Amit, Domowitz \& Fershtman, 1988; Chintagunta \& Vilcassim, 1992; Erickson, 1997) has developed tools and models to help managers better incorporate "competitive conjectures", which are mental assessments of competitors' likely next moves, into devising optimal strategies for dealing with competitive interactions. Yet, a branch of management and marketing research that focuses on managerial cognitions about competitors reveals that managers are not fully capable of analyzing the competition. Specifically, many managers make cognitive errors in identifying who their key competitors are (Clark \& Montgomery, 1999; Porac \& Thomas, 1990), in diagnosing competitors' intentions and behaviors (Moore \& Urbany, 1994; Zajac \& Bazerman, 1991), and in interpreting competitive environment in general (Dutton \& Jackson, 1987; Kiesler \& Sproull, 1982).

More germane to the current research, managerial cognition research has shown that managers are not accurate in predicting competitors' next moves (Clark \& Montgomery, 1996). Many managers also do not devote a significant amount of time and resources to making conjectures of competitors' moves because they do not see this activity as financially rewarding (Montgomery, Moore \& Urbany, 2005). Consequently, competitive conjecturing becomes a rare capability among firms (Urbany \& Montgomery, 1998).

If managers are not accurate in conjecturing their competitors' next moves, do they then tend to overestimate or underestimate the degree of threat posed by the competitors' moves? For example, in predicting the pricing actions of competitors, do managers tend to predict lower prices (more threatening) or higher prices (less threatening) than the competitors will actually charge? Research on managerial disposition suggests that many managers have competitor-oriented mindsets (Armstrong \& Collopy, 1997) and a penchant to treat competition as a zero-sum game (Griffith \& Rust, 1997). Studies also suggest that managers often are overly wary of competitors and constantly perceiving that key competitors are out to hurt their business (Kalra \& Soberman, 2007), especially when the industry already has a history of intense rivalry among existing players (Waarts \& 
Wierenga, 2000). In light of these prior findings, we hypothesize that managers will generally tend to be paranoid about their competitors' actions:

H1: In making competitive conjectures, managers tend to overestimate the degree of threat posed by competitors' next moves.

Is competitive paranoia a chronic managerial trait? In particular, will the tendency to be paranoid about competitors' actions be corrected over time as managers gains more experience in dealing with and assessing competitors? Research suggests that junior managers are more susceptible to competitor orientation biases because they lack sufficient feedback for self-evaluation and tend to take cues from formal and informal sources of guidance such as pep talks by senior management and motivational programs (which often carry "let's beat our competitors" overtones) to derive norms of beliefs about competitors' behavior (Kalra \& Soberman, 2008). However, after gaining some exposure to competition and over repeated interactions with competitors, these managers can learn to be better calibrated in their conjectures about competitors' next moves (Urbany \& Montgomery, 1998). Moore (1992) provides support for such a learning effect, in that, over repeated interactions, managers learn to better read cooperative signals sent by competitors and, accordingly, moderate their competitive stance towards competitors. In light of this evidence, we hypothesize the following:

H2: As managers gain experience in assessing and dealing with competitors, their competitive paranoia will be less pronounced.

What brings about competitive paranoia among managers in the first place? While intuition may suggest that such a bias is attributable to ignorance or lack of attentiveness to the competitive environment, evidence from the competitive analysis process actually indicates that it is the preoccupation with competitive planning activities that results in distorted beliefs about the threat posed by competitors. For example, paying too much attention to competitors' announcements may create an (unnecessary) sense of urgency to react to every move competitors make (Deshpande \& Gatignon, 1994). If managers try to read too much into every move the competitors make, they may also commit the fundamental attribution error (Fiske \& Taylor, 1991), namely, by attributing any seemingly encroaching action of a competitor to the latter's ill-intention as opposed to a circumstantial move brought about by the situation (Moore \& Urbany, 1994). In short, preoccupation with competitive planning is likely to breed competitive paranoia (Note 1):

H3: The severity of managers' competitive paranoia is positively related to the extent to which managers are preoccupied with competitive planning.

How does competitive paranoia affect firm performance? While research generally indicates that excessive competitor orientation is detrimental to firm performance because it leads one to undertake moves that are aimed at reducing competitors' profits instead of maximizing one's own profits (Armstrong \& Collopy, 1996; Griffith \& Rust, 1997), it must be noted that being paranoid about competitors does not necessarily equate to acting in a highly competitive manner. Clark and Montgomery's (1996) study has in fact shown that having a paranoia about competition (in their case, measured by the number of competitive reactions a firm perceives its competitors to have made to its own actions) is positively related to firm performance. The authors' explanation is that paranoia increases vigilance and in turn promotes performance-enhancing decisions. At the same time, it ought to matter what form of paranoia helps improve performance. When competitive paranoia is widespread and of an "amateurish" form driven mainly by inexperience and distorted beliefs about the competition, managerial actions tend to be aimed at retaliating against the competitor or reducing competitors' payoffs (Kalra \& Soberman, 2008). Accordingly, firm performance may not be optimal. In contrast, when paranoia matures over time to take on a discriminating form, it is likely to represent a seasoned, learned response to genuinely threatening signals in the competitive environment, accompanied by a vigilant and cautious manner of action planning aimed at defending one's market position or circumventing competitive threat. The resultant strategic decisions will therefore be more prudent. Based on this reasoning, we expect competitive paranoia that grows over time to be associated with improvements in firm performance:

H4: Growth in competitive paranoia over time is related to improvement in firm performance whereas initial paranoia does not have an impact on firm performance.

\section{Method}

\subsection{Setting}

To test the above hypotheses, we conducted a study using the Markstrat simulation (Larréché \& Gatignon, 2003) involving student participants at a business school in Singapore. Strategy and marketing researchers regularly use Markstrat as a realistic setting for studying competitive decision making and behavior (Larréché, 1987). In 
Markstrat, participants assume the role of firm managers and undertake strategic marketing actions on behalf of their simulated firms within a constantly changing competitive market environment. In each decision cycle, participants have to predict what their competitors will do next before deciding their own moves, thus allowing us to examine the degree of paranoia in their conjectures. Furthermore, the simulation is highly engaging as it participants make difficult decisions in reaction to evolving scenarios over multiple periods (Larréché, 1987). External validity is achieved because the simulated environment is highly realistic (Aronson, Wilson \& Akert, 1994).

In our study, participants were divided into teams that represented competing firms. Altogether, 72 firms were formed across 16 industries, with four or five teams competing in each industry. All industries had identical starting conditions with identical starting performance levels across firms. The entire simulation lasted eight week-long periods. In each period, participants reviewed financial reports and market research statistics (including competitive intelligence data) and made a set of marketing decisions including research and development for new products, price-setting, advertising, and sale force allocation strategies. Each firm initially marketed two brands of a product and could develop new brands, modify existing brands, or withdraw brands in subsequent periods. At the end of each period, the Markstrat software generated the performance results for each firm based on pre-determined response models (Gatignon, 1987).

\subsection{Measures}

\subsubsection{Competitive Paranoia}

We measured the degree of competitive paranoia by comparing participants' conjectures of their key competitors' moves with the competitors' actual moves. As price and advertising expenditures are highly visible marketing mix elements and are commonly used as representative measures of competitive actions (see e.g., Montgomery, Moore \& Urbany, 2005), we focused on conjectures regarding these two moves. We took two measures at two points during the eight-week simulation between periods $3 \& 8$. At the end of period 3 , in a team based survey, participants were asked to identify the strongest competitor brand for the most important brand of their own firm, and then were asked to predict the price and advertising expenditure of competitor for that brand in Period 4 (i.e., the pricing and advertising moves that their key competitor was likely to make). After period 4, competitive paranoia as computed by percentage deviations of participants' predictions from the actual pricing and advertising decisions made by the competitor. Competitive paranoia was indicated by a negative (positive) percentage deviation of each firm's prediction from its key competitor's price (advertising expenditure) from the actual figure. At the end of Period 6, the survey was re-administered for predicting moves of competitor in Period 7 and competitive paranoia was computed similarly.

\subsubsection{Preoccupation with Competitive Planning}

As part of each survey, we included a question asking each firm to indicate the average number of hours they spent per week per team member on competitive analysis and planning. Because the Markstrat participant handbook prescribes two to four hours as the amount of time each participant needs to devote to decision planning in each period (Larréché \& Gatignon, 2003) and teams' responses in the survey ranged from two to 20 hours with a mean of 6.65 hours, this measure represented a good proxy for "preoccupation".

\subsubsection{Firm Performance}

We measured firm performance by computing the percentage growth in a firm's net contribution (i.e., the firm's net profit figure) over a certain number of periods. Specifically, for the analysis reported below, we computed percentage growth in net contribution from Period 3 to Period 4, from Period 3 to Period 7, as well as from Period 3 to Period 8 . Net contribution is an appropriate measure of firm performance because it was an outcome variable for which teams were accountable and on which they were motivated to improve (not only was their weekly marketing budget dependent on the amount of net contribution they achieved, but as much as $20 \%$ of their course grade was also based on a financial outcome score which included net contribution performance).

\subsubsection{Control Measures}

In each survey, we had several control variables representing characteristics of the firm and the environment. Firstly, we used a measure for winning intent to control for how strongly intent the firm is in overcoming the competition (Malter \& Dickson, 2001). Secondly, a measure for environmental hostility was included to account for the effect of the harshness of the competitive environment (Miller, 1987). Thirdly, we controlled for differences in proficiency with the Markstrat software using a measure for technical understanding (Malter \& Dickson, 2001). All measures had previously been validated through repeated surveys in the Markstrat environment, with alphas exceeding .70 (see Table 1 for scale items and reliability indices). 
Table 1 . Scale items and reliability scores of control and corroborative variables

\begin{tabular}{|c|c|c|}
\hline Scale & Adapted from & Cronbach Alpha ${ }^{a}$ \\
\hline $\begin{array}{l}\text { Winning Intent } \\
\text { - It is a must for us to outperform the other teams in the Markstrat simulation. } \\
\text { - Finishing last in the Markstrat simulation would have been unacceptable to us. } \\
\text { - We try harder than usual in the Markstrat simulation to outperform the other teams in our } \\
\text { market. }\end{array}$ & $\begin{array}{c}\text { Malter \& } \\
\text { Dickson (2001) }\end{array}$ & .72 \\
\hline $\begin{array}{l}\text { Environmental Hostility } \\
\text { - Doing business in this industry is very stressful and very hard to keep afloat. } \\
\text { - In recent periods, the activities of our competitors have become far more hostile. } \\
\text { - In recent periods, the activities of our competitors have affected our team in many more areas } \\
\text { (e.g., pricing, advertising, sales force, etc.). }\end{array}$ & Miller (1987) & .73 \\
\hline $\begin{array}{l}\text { Technical Understanding (of Markstrat) } \\
\text { - I have a real in-depth understanding of how Markstrat works. } \\
\text { - I know the Markstrat software inside out. } \\
\text { - I have a really good grasp of how to use the market research and analytical tools in Markstrat. }\end{array}$ & $\begin{array}{c}\text { Malter \& } \\
\text { Dickson (2001) }\end{array}$ & .77 \\
\hline $\begin{array}{l}\text { Competitive Vigilance } \\
\text { - As a team, we pay close attention to competitors' activities. } \\
\text { - We keep a close watch on our competitors' product development strategies. } \\
\text { - We monitor which competitor products are successful in the market. } \\
\text { - We keep a close watch on our competitors' pricing tactics. } \\
\text { - We spend a lot of time discussing competitors' strategies. }\end{array}$ & $\begin{array}{l}\text { Voss \& Voss } \\
\text { (2000) }\end{array}$ & .82 \\
\hline
\end{tabular}

${ }^{\text {a }}$ Computed based on a pool of 356 survey responses from multiple studies.

\section{Analysis and Results}

\subsection{Existence and Extent of Competitive Paranoia}

Table 2 shows the distribution of percentage deviations of firms' predictions of key competitors' price and advertising expenditure from the actual figures decided by the respective key competitors. For the first round of predictions (between Period 3 and Period 4), after removing outliers (by deleting highly inaccurate cases with percentage deviations that exceeded +2 or -2 standard deviations from the mean percentage deviation), the mean and median percentage deviation of price predictions from the actuals were both negative, with a $95 \%$ confidence interval for the mean that is within the negative region. This indicates that teams generally inaccurately conjectured that their key competitors' prices would be lower (i.e., more threatening) than those prices actually turned out to be. Likewise, in the first round of predictions, the mean and median percentage deviation of advertising expenditure predictions from the actuals (excluding outliers) were both positive, with a $95 \%$ confidence interval for the mean that is within the positive region. This indicates that teams generally inaccurately conjectured that their key competitors' advertising expenditures would be higher (i.e., more threatening) than those expenditures turned out to be. These results provide support for $\mathrm{H}_{1}$, which states that managers tend to overestimate the threat posed by competitors' next moves. 
Table 2. Distribution of percentage deviations in predictions about competitors' next moves (between period 3 and period $4 \&$ between period 6 and period 7)

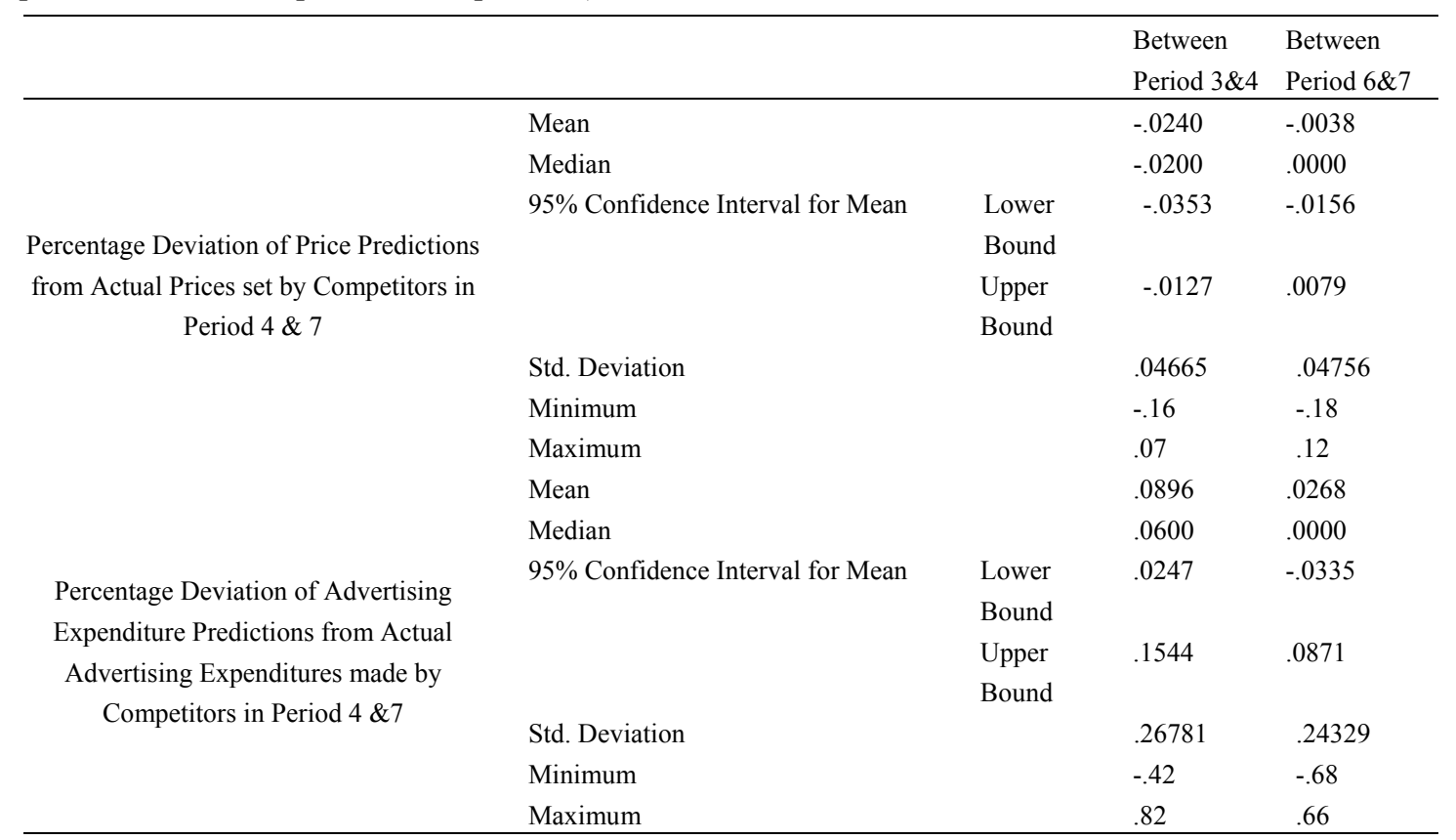

In contrast, in the second round of predictions (between Period 6 and Period 7), competitive paranoia was noticeably less pronounced. The mean and median percentage deviation of price predictions became less negative, and the mean and median percentage deviation of advertising expenditure predictions became less positive. The $95 \%$ confidence intervals for both means now included the value zero. This indicates that participants' conjectures were no longer biased towards an overestimation of competitors' threat. Furthermore, a paired samples t-test of the difference between the percentage deviation of price predictions in the first round of predictions and that in the second round of predictions indicates that the percentage deviation became significantly higher (i.e., less paranoid) in the second round ( $t$ mean difference $=2.47 ; p<.05$ ). The same test for advertising expenditure predictions indicates that the percentage deviation became lower (i.e., less paranoid), albeit marginally in statistical terms, in the second round of predictions $(t$ mean difference $=1.73 ; p<.10)$. When the percentage deviations were combined into a single index score (with the sign for price prediction deviations reversed such that the higher the index score, the greater the degree of paranoia indicated), the combined index score was significantly lower in the second round of predictions $(t$ mean difference $=3.311 ; p$ $<.01)$. Overall, the evidence lend support to $\mathrm{H}_{2}$, which states that competitive paranoia will be reduced as managers gain experience in assessing and dealing with competitors over time. Apparently, this is not because managers become complacent about competition over time. In fact, when we compared the degrees of competitive vigilance (using a measure adapted from Voss \& Voss 2000) between the two points in time, we found that the teams became more vigilant during the second round of competitive predictions $(t$ mean difference $=2.225 ; p<.05$ ).

\subsection{Preoccupation with Competitive Planning as a Cause of Paranoia}

We performed regression analysis to test whether preoccupation with competitive planning influenced the degree of competitive paranoia exhibited by the Markstrat teams. The combined index score for competitive paranoia was used as the dependent variable, whereas the preoccupation measure was entered as the independent variable. Several control measures, namely, for winning intent, environmental hostility, and technical understanding, were first entered into the regression model to account for possible alternative explanations for paranoia, as was a dummy for the round of prediction, to account for the experience effect. The results (see Table3) show that preoccupation with competitive planning had a positive and significant effect on the degree of competitive paranoia (standardized $\beta=.18, p<.05$ ), and the entrance of this independent variable significantly increased the explanatory power of the regression model (from $F=2.847, d f=4,138,142, p<.05 ; R^{2}=.08$ to $F$ $\left.=3.255, d f=5,137,142, p<.01 ; R^{2}=.11\right)$. This evidence provides support for $\mathrm{H}_{3}$, which states that preoccupation with competitive planning breeds competitive paranoia. 
Table 3. Regression results for driver of competitive paranoia

\begin{tabular}{|c|c|c|}
\hline \multirow{2}{*}{ Independent Variables } & \multicolumn{2}{|c|}{ Dependent Variable: Index Score for Competitive Paranoia } \\
\hline & Model with control variables only & Model with control variables plus predictor variables \\
\hline \multicolumn{3}{|l|}{ Predictor Variable: } \\
\hline Preoccupation with Competitive Planning & - & $.18^{*}$ \\
\hline \multicolumn{3}{|l|}{ Control Variables: } \\
\hline Winning Intent & .08 & .07 \\
\hline Environmental Hostility & -.07 & -.11 \\
\hline Technical Understanding & -.07 & -.07 \\
\hline Dummy for Round of Prediction & $-.22 *$ & $-.20^{*}$ \\
\hline \multicolumn{3}{|l|}{ Model Statistics: } \\
\hline F-value & $2.847^{*}$ & $3.255^{* *}$ \\
\hline$R^{2}$ & .08 & .11 \\
\hline
\end{tabular}

$* \mathrm{p}<.05, * * \mathrm{p}<.01$.

\subsection{Performance Consequence of Competitive Paranoia}

Three sets of regression analysis were performed: one with the percentage growth in net contribution from Period 3 to Period 4, a second with the percentage growth in net contribution from Period 3 to Period 7, and a third with the percentage net contribution from Period 3 to Period 8 as the dependent variables respectively. In each regression, either the initial level of competitive paranoia (the index score in the first round of predictions) or the growth in competitive paranoia (the difference in index scores between the second and the first round of predictions) was the independent variable, and 15 dummies were added to control for industry differences in performance. The results (see Table 4) show that while initial competitive paranoia had no significant effect on improvement in firm performance in the early stage of the simulation (from Period 3 to Period 4) (standardized $\beta=.004, p=.98$ ), the growth in paranoia was positively related to improvement in firm performance over time. Specifically, growth in competitive paranoia had a significant positive effect on firm performance growth from Period 3 to Period 7 (standardized $\beta=.23, p<.05$ ) and also positive, albeit marginally significant, effect on firm performance growth from Period 3 to Period 8 (standardized $\beta=.21, p<.10$ ). The latter two regression models also demonstrated high explanatory power $\left(F=3.035, d f=16,55,71, p<.01 ; R^{2}=.47\right.$ and $F=2.613, d f=$ $16,55,71, p<.01 ; R^{2}=.43$ respectively). Judging from the low correlation between the competitive paranoia index in the first round of predictions and that in the second round of predictions $(r=.08 ; p=.46)$, it also appears that the two occurrences of paranoia are of different forms. The former form is likely to be more amateurish and innate (given it is also more widespread), whereas the latter form seems to be a learned and seasoned capability of managers. This also makes sense in light of earlier finding that the competitive paranoia became less prevalent and yet competitive vigilance levels became higher during the second round of predictions. Overall, these results support $\mathrm{H}_{4}$, which states that competitive paranoia yields performance benefits when it has matured over time. 
Table 4. Regression results for performance effects

\begin{tabular}{|c|c|c|c|c|c|c|}
\hline \multirow[b]{3}{*}{ Independent Variables } & \multicolumn{6}{|c|}{ Dependent Variables } \\
\hline & \multicolumn{2}{|c|}{$\begin{array}{l}\text { Percentage Growth } \\
\text { Contribution from } \\
\text { Period } 3 \text { to Period } 4 \\
\end{array}$} & \multicolumn{2}{|c|}{$\begin{array}{l}\text { Percentage Growth } \\
\text { Contribution from } \\
\text { Period } 3 \text { to Period } 7 \\
\end{array}$} & \multicolumn{2}{|c|}{$\begin{array}{l}\text { Percentage Growth in Net } \\
\text { Contribution from } \\
\text { Period } 3 \text { to Period } 8\end{array}$} \\
\hline & $\begin{array}{l}\text { Model with } \\
\text { control } \\
\text { variables only }\end{array}$ & $\begin{array}{l}\text { Model with } \\
\text { control } \\
\text { variables plus } \\
\text { key predictor } \\
\text { variable } \\
\end{array}$ & $\begin{array}{l}\text { Model with } \\
\text { control } \\
\text { variables only }\end{array}$ & $\begin{array}{l}\text { Model with } \\
\text { control } \\
\text { variables plus } \\
\text { key predictor } \\
\text { variable }^{\text {a }} \\
\end{array}$ & $\begin{array}{l}\text { Model with } \\
\text { control } \\
\text { variables only }\end{array}$ & $\begin{array}{l}\text { Model with } \\
\text { control } \\
\text { variables plus } \\
\text { key predictor } \\
\text { variable }^{\text {a }} \\
\end{array}$ \\
\hline $\begin{array}{l}\text { Initial Competitive } \\
\text { Paranoia Level }\end{array}$ & - & .004 & - & - & - & - \\
\hline $\begin{array}{l}\text { Growth in Competitive } \\
\text { Paranoia } \\
\text { Control Variables: }\end{array}$ & - & - & - & $.23^{*}$ & - & $.21^{\dagger}$ \\
\hline $\begin{array}{l}\text { Industry Dummies } \\
\text { (not listed here for } \\
\text { simplicity) } \\
\text { Model Statistics: }\end{array}$ & \multicolumn{2}{|c|}{ At least one is significant* } & \multicolumn{2}{|c|}{ At least one is significant* } & \multicolumn{2}{|c|}{ At least one is significant* } \\
\hline F-value & $2.122 *$ & $1.954 *$ & $2.783 * *$ & $3.035^{* *}$ & $2.484 * *$ & $2.613 * *$ \\
\hline$R^{2}$ & .37 & .37 & .43 & .47 & .40 & .43 \\
\hline
\end{tabular}

${ }^{\text {a }} \mathrm{F}$-statistic change is significant when predictor variable is added to the model.

${ }^{\dagger} \mathrm{p}<.10,{ }^{*} \mathrm{p}<.05, * * \mathrm{p}<.01$.

\section{Discussion}

The major findings of this study are threefold. First, relatively inexperienced managers tend to be overly paranoid about the competition, as evidenced by the extent to which they overestimate the threat posed by their key competitors' next moves in the early phase of the Markstrat simulation. However, such a competitive paranoia tends to be less widespread over time as managers gain experience in assessing and interacting with competitors, as evidenced by the lesser extent of threat estimation in the late phase of the simulation. Second, regardless of whether managers are experienced or not, a key factor driving the degree of competitive paranoia in managers is their preoccupation with competitive planning, as indicated by the positive relationship between the amount of time participants spent on competitive analysis and their competitive paranoia levels. Third, while the initial competitive paranoia level does not immediately help in improving firm performance, the growth in paranoia positively influences firm performance improvement over time. More specifically, firms that exhibited increased paranoia levels between the early and the late phase of the simulation showed greater percentage growth in their profitability.

\subsection{Theoretical Implications}

Collectively, the study findings shed light on the nature, drivers, and outcomes of competitive paranoia, a judgmental bias that is not yet well understood in the competitive cognition and competitive marketing behavior literatures. These findings hold several important implications for the theoretical development concerning competitive paranoia. First, in contrast to the simplistic view of managerial behavior as being overly competitive in a chronic fashion (e.g., Armstrong \& Collopy, 1996; Griffith \& Rust, 1997), the results of this study point to a richer understanding of the bias as being self-adjustable over time. With greater exposure and experience in reading signals in the competitive environment, managers can learn to be become less paranoid (Moore, 1992; Urbany \& Montgomery, 1998), even as they maintain their vigilance over competitors. Second, in contrast to intuitive expectations that the cause of paranoia is simply ignorance or inattention to aspects of the competitive environment, the finding about the preoccupation effect suggests that the paranoia bias is brought about by an excessive focus on perhaps limited aspects of competition. Here, theoretical development can draw upon insights from the work on "blinders" or "blind spots" (Moore \& Urbany, 1994; Zajac \& Bazerman, 1991) to uncover the exact causal mechanisms underlying paranoid thinking in competition. Finally, in contrast to initial understanding of competitive paranoia as taking only a single form (Clark \& Montgomery, 1996), the performance effects findings in this study suggest that competitive paranoia, even if it is not reduced over time, can evolve into a mature form that can in fact be desirable in enhancing the quality of competitive decisions and, 
consequently, firm performance. Here, theoretical development can perhaps benefit from linking this mature, learned form of paranoia to the capabilities perspective (Day, 1994; Dickson, Farris \& Verbeke, 2001). Emerging from such a linkage could be an enlightened view that sees experienced, seasoned paranoia as a desirable defensive mechanism that constitutes a performance-enhancing capability of the firm.

\subsection{Managerial Implications}

The study findings also hold a number of useful implications for managerial practice. Foremost, the findings suggest that paranoid feelings about the competition can be quite widespread, especially among inexperienced managers. In an industry setting where competing firms do not well understand one another, industry rivalry can become highly intense due to firms' frequent overreactions to one another's actions arising from mutual paranoia. This can be disruptive to industry growth, although over time as the industry matures and is staffed with experienced managers, the problem would somewhat correct itself. Another way to rectify excessive paranoia, as suggested by the study findings, is to train managers to avoid getting preoccupied with competitive planning. Managers should be advised, in marketing analysis and planning, to adopt a more balanced orientation and to pay commensurate attention to customer issues (Day \& Nedungadi, 1994), so that unnecessary paranoia will subside. On the other hand, as the study findings also suggest, competitive paranoia is not necessarily bad. When it is of a mature, learned kind, as when a seasoned industry veteran can sense looming threats from competition and, consequently, takes action to heighten the firm's defense against the competitors, competitive performance can in fact improve. The implication for management is therefore to be able to develop such a form of selective and discerning paranoia.

\subsection{Moving Forward}

Notwithstanding the contributions highlighted above, this study has limitations which present opportunities for future research. First, this study examines competitive paranoia only in terms of biasness in conjecturing competitors' pricing and advertising moves in the immediate term. Although this represents a further step from Clark and Montgomery's (1996) simple operationalization of paranoia as the number of competitive reactions perceived, future studies could explore additional forms and operationalizations, possibly involving conjectures about competitive actions in longer time horizons and over a wider range of marketing mix elements, so that a more comprehensive understanding of competitive paranoia can be achieved. Second, this study investigates the effect of only one driver of competitive paranoia, namely preoccupation with competitive planning, and direct performance effects of competitive paranoia in terms of growth in firm profitability. Although this contributes a critical baseline understanding of the primary causes and consequences of competitive paranoia, future studies could examine more complex relationships including, but not limited to, the mediating mechanisms between the drivers, competitive paranoia, and firm performance, as well as performances effects over a wider range of performance variables. The research community can then benefit from richer perspectives of when competitive paranoia is truly beneficial and how firms can cultivate desirable forms of paranoia while preventing undesirable forms of it. Finally, as an extension to the simulation-based methodology undertaken in this study, future studies could utilize a variety of alternative methods which bring valuable field data to bear. The research community can then triangulate the key findings across different methods and settings.

\section{References}

Aaker, D. (2007). Strategic Market Management. New York, NY: John Wiley \& Sons.

Amit, R., Domowitz, I., \& Fershtman, C. (1988). Thinking One Step Ahead: The Use of Conjectures in Competitor Analysis. Strategic Management Journal, 9(5), 431-442. http://dx.doi.org/10.1002/smj.4250090504

Armstrong, J. S., \& Fred, C. (1996). Competitor Orientation: Effects of Objectives and Information on Managerial Decisions and Profitability. Journal of Marketing Research, 33(2), 188-199. http://dx.doi.org/10.2307/3152146

Aronson, E., Wilson, T. D., \& Akert, R. M. (1994). Social Psychology: The Heart and the Mind. New York, NY: Harper Collins College Publishers.

Chintagunta, P. K., \& Vilcassim, N. J. (1992). An Empirical Investigation of Advertising Strategies in a Dynamic Duopoly. Management Science, 38(9), 1230-1244. http://dx.doi.org/10.1287/mnsc.38.9.1230

Clark, B. H., \& Montgomery, D. B. (1996). Perceiving Competitive Reactions: The Value of Accuracy (and Paranoia). Marketing Letters, 7(2), 115-129. http://dx.doi.org/10.1007/BF00434904 
Clark, B. H., \& Montgomery, D. B. (1998). Deterrence, Reputations, and Competitive Cognition. Management Science, 44(1), 62-82. http://dx.doi.org/10.1287/mnsc.44.1.62

Clark, B. H., \& Montgomery, D. B. (1999). Managerial Identification of Competitors. Journal of Marketing, 63(3), 67-83. http://dx.doi.org/10.2307/1251776

Curren, M. T., Folkes, V. S., \& Steckel, J. H. (1992). Explanations for Successful and Unsuccessful Marketing Decisions: The Decision Maker's Perspective. Journal of Marketing, 56(2), 18-31. http://dx.doi.org/10.2307/1252039

Czepiel, J. A. (1992). Competitive Marketing Strategy. Englewood Cliffs, NJ: Prentice Hall.

Day, G. S. (1994). The Capabilities of Market-Driven Organizations. Journal of Marketing, 58(4), 37-52. http://dx.doi.org/10.2307/1251915

Day, G. S., \& Nedungadi, P. (1994). Managerial Representations of Competitive Advantage. Journal of Marketing, 58(April), 31-44. http://dx.doi.org/10.2307/1252267

Day, G. S., \& Wensley, R. (1988). Assessing Advantage: A Framework for Diagnosing Competitive Superiority. Journal of Marketing, 52(April), 1-20. http://dx.doi.org/10.2307/1251261

Deshpande, R., \& Gatignon, H. (1994). Competitive Analysis. Marketing Letters, 5(3), 271-287. http://dx.doi.org/10.1007/BF00993906

Dickson, P. R., Farris, P. W., \& Verbeke, W. M. I. (2001). Dynamic Strategic Thinking. Journal of the Academy of Marketing Science, 29(3), 216-237. http://dx.doi.org/10.1016/0022-4359(94)90025-6

Dickson, P. R., \& Urbany, J. E. (1994). Retailer Reactions to Competitive Price Changes. Journal of Retailing, $70(1), 1-21$.

Dutton, J. E., \& Jackson, S. E. (1987). Categorizing Strategic Issues: Links to Organizational Actions. Academy of Management Review, 12(1), 76-90.

Erickson, G. M. (1997). Note: Dynamic Conjectural Variations in a Lanchester Oligopoly. Management Science, 43(11), 1603-1608. http://dx.doi.org/10.1287/mnsc.43.11.1603

Fiske, S. T., \& Taylor, S. E. (1991). Social Cognition (2nd ed.). New York: McGraw-Hill.

Gatignon, H. (1987). Strategic Studies in Markstrat. Journal of Business Research, 15(6), 469-480. http://dx.doi.org/10.1016/0148-2963(87)90032-4

Glazer, R., Steckel, J. H., \& Winer, R. H. (1992). Locally Rational Decision Making: The Distracting Effect of Information on Managerial Performance. Management Science, 38(2), 212-226. http://dx.doi.org/10.1287/mnsc.38.2.212

Griffith, D. E., \& Rust, R. T. (1997). The Price of Competitiveness in Competitive Pricing. Journal of the Academy of Marketing Science, 25(2), 109-116. http://dx.doi.org/10.1007/BF02894346

Hamel, G., \& Prahalad, C. K. (1989). Strategic Intent. Harvard Business Review, 67(3), 63-78.

Heil, O. P., \& Helsen, K. (2001). Toward an Understanding of Price Wars: Their Nature and How They Erupt. International Journal of Research in Marketing, 18, 83-98. http://dx.doi.org/10.1016/S01678116(01)00033-7

Kalra, A., \& Soberman, D. A. (2008). The Curse of Competitiveness: How Advice from Experienced Colleagues and Training Can Hurt Marketing Profitability. Journal of Marketing, 72(3), 32-47. http://dx.doi.org/10.1509/jmkg.72.3.32

Kiesler, S., \& Sproull, L. (1982). Managerial Response to Changing Environments: Perspectives on Problem Sensing from Social Cognition. Administrative Science Quarterly, 27, 548-570. http://dx.doi.org/10.2307/2392530

Larréché, J. C. (1987). On Simulations in Business Education and Research. Journal of Business Research, 15(6), 559-571. http://dx.doi.org/10.1016/0148-2963(87)90039-7

Larréché, J. C., \& Gatignon, H. (2003). Markstrat Online. Paris: StratX International.

Leeflang, P. S. H., \& Wittink, D. K. (1996). Competitive Reaction versus Consumer Response: Do Managers Overreact? International Journal of Research in Marketing, 13(2), 103-119. http://dx.doi.org/10.1016/0167-8116(96)00003-1 
Malter, A. J., \& Dickson, P. R. (2001). The Effect of Individual Learning on Competitive Decision-Making and Firm Performance. International Journal of Research in Marketing, 18(1/2), 99-117. http://dx.doi.org/10.1016/S0167-8116(01)00034-9

Miller, D. (1987). The Structural and Environmental Correlates of Business Strategy. Strategic Management Journal, 8(1), 55-76. http://dx.doi.org/10.1002/smj.4250080106

Montgomery, D. B., Moore, M. C., \& Urbany, J. E. (2005). Reasoning about Competitive Reactions: Evidence from Executives. Marketing Science, 24(1), 138-149. http://dx.doi.org/10.1287/mksc.1040.0076

Moore, M. C. (1992). Signals and Choices in a Competitive Interaction: The Role of Moves and Messages. Management Science, 38(April), 483-500. http://dx.doi.org/10.1287/mnsc.38.4.483

Moore, M. C., \& Urbany, J. E. (1994). Blinders, Fuzzy Lenses, and the Wrong Shoes: Pitfalls in Competitive Conjecture. Marketing Letters, 5(3), 247-258. http://dx.doi.org/10.1007/BF00993904

Nunnally, J. C. (1978). Psychometric Theory (2nd ed.). New York: McGraw-Hill.

Porac, J. F., \& Thomas, H. (1990). Taxonomic Mental Models in Competitor Definition. Academy of Management Review, 15(2), 224-240.

Porter, M. E. (1980). Competitive Strategy: Techniques for Analyzing Industries and Competitors. New York: Free Press.

Prabhu, J., \& Stewart, D. (2001). Signaling Strategies in Competitive Interaction: Building Reputations and Hiding the Truth. Journal of Marketing Research, 38(1), 62-72. http://dx.doi.org/10.1509/jmkr.38.1.62.18826

Urbany, J., \& Montgomery, D. (1998). Rational Strategic Reasoning: An Unnatural Act? Marketing Letters, 9(3), 285-299. http://dx.doi.org/10.1023/A:1008024306716

Voss, G. B., \& Voss, Z. G. (2000). Strategic Orientation and Firm Performance in an Artistic Environment. Journal of Marketing, 64(1), 67-83. http://dx.doi.org/10.1509/jmkg.64.1.67.17993

Waarts, E., \& Wierenga, B. (2000). Explaining Competitive Reactions to New Product Introductions: The Roles of Event Characteristics, Managerial Interpretation, and Competitive Context. Marketing Letters, 11(1), 67-79. http://dx.doi.org/10.1023/A:1008102927459

Zajac, E. J., \& Bazerman, M. H. (1991). Blind Spots in Industry and Competitor Analysis: Implications of Interfirm (Mis) Perceptions for Strategic Decisions. Academy of Management Review, 16(1), 37-56.

Note

Note 1. Note that preoccupation with competitive planning as conceived of here is independent of the manager's experience, which is about his/her tenure on the job. Just as an inexperienced manager can be either preoccupied or not preoccupied with competitive planning, so can an experienced manager.

\section{Copyrights}

Copyright for this article is retained by the author(s), with first publication rights granted to the journal.

This is an open-access article distributed under the terms and conditions of the Creative Commons Attribution license (http://creativecommons.org/licenses/by/3.0/). 